\title{
Right thigh pain
}

\section{J. Huynh • H. Obaid}

Published online: 30 December 2014

(C) ISS 2014

\section{Right thigh pain}

\section{History:}

Seventy-one year old female presenting with long-standing non-traumatic mid-right thigh pain (Figs. 1 and 2).

Fig. 1 Frontal radiographs of right hip and femur
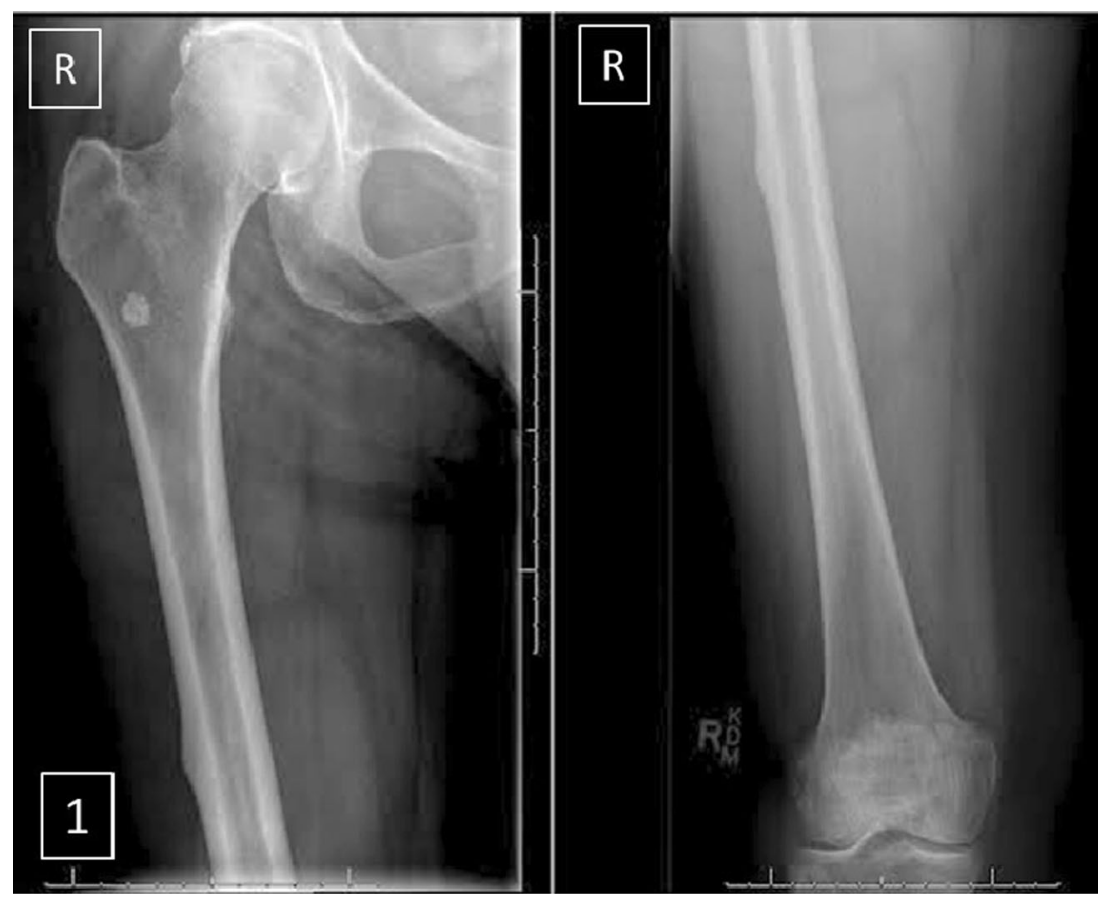

The diagnosis can be found at doi: 10.1007/s00256-014-2088-y

J. Huynh $\cdot$ H. Obaid

Royal University Hospital, College of Medicine, University of

Saskatchewan, 103 Hospital Drive, Saskatoon, SK, Canada

J. Huynh $(\bowtie)$

Royal University Hospital, 103 Hospital Drive, Saskatoon, SK,

Canada

e-mail: jah354@mail.usask.ca 


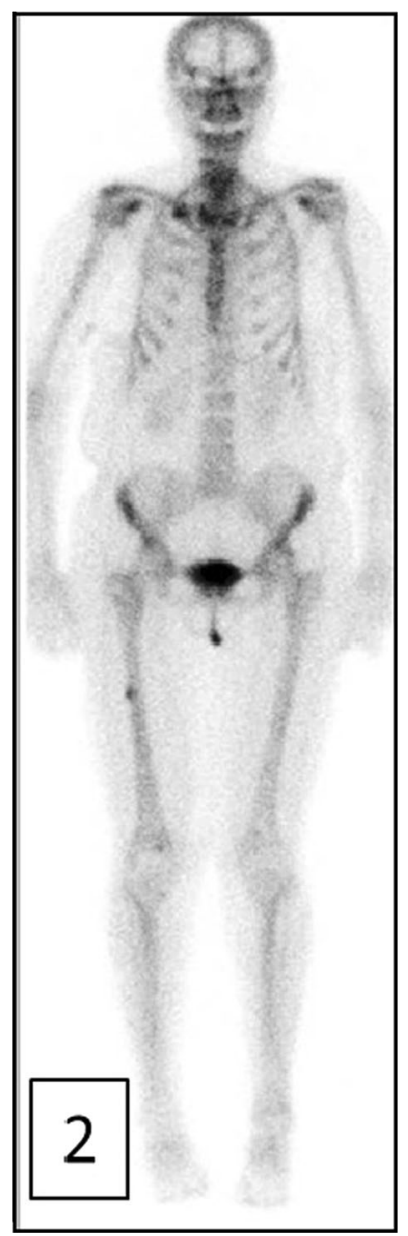

Fig. 2 Anterior projection of patient's radioisotope bone scan 